\title{
Beyond Quantitative Decline: Conceptual Shifts in Adolescents' Development of Interest in Mathematics
}

\author{
Anne C. Frenzel \\ University of Augsburg \\ Anna-Lena Dicke \\ University of Tuebingen
}

\author{
Reinhard Pekrun \\ University of Munich \\ Thomas Goetz \\ University of Konstanz and \\ Thurgau University of Teacher Education
}

\begin{abstract}
Research has shown that the average values for academic interest decrease during adolescence. Looking beyond such quantitative decline, we explored qualitative change of interest in the domain of mathematics across adolescence. Study 1 was based on a longitudinal data set (annual assessments from Grade 5 to Grade $9 ; N=3,193$ ). Latent variable modeling showed that the measurement coefficients of the latent variable of interest (intercepts, structural weights, and error variances) significantly differed across time points, indicating structural changes of the construct. Study 2 was based on interviews with adolescents (Grades 5 and 9, $N=70$ ). Cognitive validation was used to explore differences in subjective concepts of interest across age groups. As expected, there were significant age-related differences, indicating a shift from an affect-laden concept in 5th grade to a more cognitively oriented concept in 9 th grade. The findings suggest that developmental research should integrate quantitative and qualitative perspectives of construct change over time and pay more attention to issues of measurement invariance and qualitative changes of constructs over time.
\end{abstract}

Keywords: interest, adolescence, cognitive validation, measurement invariance, psychological assessment

Clearly, engaging in a topic due to interest is highly desirable: Not only is the state of being interested typically charged with positive feelings but also the performance of interested actors is typically high. Therefore, a key goal of educators is to raise or at least maintain students' interests in school subjects. Unfortunately, this often seems to be an uphill battle, particularly for educators of adolescents (Hidi \& Harackiewicz, 2000). There is abundant empirical evidence of downward developmental trends in academic interest and related variables during the elementary and secondary school years, particularly in the domain of mathematics (Eccles et al., 1983; Eccles, Adler, \& Meece, 1984; Eccles et al., 1989; Fredricks \& Eccles, 2002; Frenzel, Goetz, Pekrun, \& Watt, 2010;

Anne C. Frenzel, Department of Psychology, University of Augsburg, Augsburg, Germany; Reinhard Pekrun, Department of Psychology, University of Munich, Munich, Germany; Anna-Lena Dicke, Department of Education, Center for Educational Science and Psychology, University of Tuebingen, Tuebingen, Germany; Thomas Goetz, Department of Empirical Educational Research, University of Konstanz, Konstanz, Germany, anc Thurgau University of Teacher Education, Kreuzlingen, Switzerland.

This research was funded in part by German Research Foundation Grant PE320/11-1/2/3/4 awarded to Reinhard Pekrun. Thanks to Elisabeth J. Stephens for her assistance in article preparation.

Correspondence concerning this article should be addressed to Anne C. Frenzel, Department of Psychology, University of Augsburg, Universitaetsstrasse 10, 86159 Augsburg, Germany. E-mail: anne.frenzel@phil.uniaugsburg.de
Gottfried, Fleming, \& Gottfried, 2001; Jacobs, Lanza, Osgood, Eccles, \& Wigfield, 2002; Köller, Baumert, \& Schnabel, 2001; Spinath \& Steinmayr, 2008; Watt, 2004; Wigfield, Eccles, Mac Iver, Reuman, \& Midgley, 1991). Such declines in academic interest have been explained by factors inherent in age-related changes. For instance, the increased complexity of academic content and thus the related increased necessity to invest effort results in a diminished intrinsic attractiveness of the respective domains (Hidi, 2000; Zimmerman \& Kitsantas, 1999). In addition, interest development likely involves moving from a boundless energy to explore and learn any new skill in childhood to only a few, selected fields of interest later on (Baumert \& Köller, 1998; Todt \& Schreiber, 1998; Tracey, 2001). This results in a pattern of an overall average decline in interest in most fields over time. Furthermore, during adolescence, increased social interests seem to compete with academic interests and therefore negatively influence academic interest trajectories (Hidi, 2000).

Looking at the quantitative decline of average academic interest during adolescence as a-sad but true-normative phenomenon, in the present research, we sought to contribute to the picture of interest development by taking a more qualitative perspective. We suspected that there is more to interest development during adolescence than mere quantitative declines of average scores. We hypothesized that the construct also undergoes structural changes during this developmental period. Below, we first detail our own general understanding of the construct of interest and then present our hypotheses on qualitative changes of interest. 


\section{The Construct of Interest}

Contemporary approaches define interest as a motivational variable that directs an individual's attention to specific objects, stimuli, and events and fuels their engagement with specific activities (Ainley, Hidi, \& Berndorff, 2002; Barron, 2006; Hidi, 2000; Krapp, 2000; Renninger, 2000; Renninger \& Hidi, 2011; Schiefele, 1998; Silvia, 2006). Interest is an important force determining the quality of learning (Schiefele, Krapp, \& Winteler, 1992). As such, interest is thought to promote achievement and excellence in educational contexts

Three important characteristics of the construct have been identified, including its state- and traitlike character, its content specificity, and its multicomponent nature. Regarding interest as state versus trait, researchers differentiate between situationally triggered interest in a particular topic or activity at a given moment (situational interest) and more generalized personal interest in a topic or activity (individual interest; Hidi, 1990; Krapp, 2000; Renninger, 2000; Schiefele, 1991). The present study addresses adolescents' individual interest.

Second, interest is typically considered content specific (Hidi \& Renninger, 2006; Schiefele, 1991). It is often referred to as an evaluative orientation toward specific classes of objects, stimuli, events, or activities. By implication, a student may be highly interested in literature but not in mathematics, or vice versa (see Bong, 2001; Goetz, Cronjaeger, Frenzel, Lüdtke, \& Hall, 2010; Goetz, Frenzel, Pekrun, Hall, \& Lüdtke, 2007, for the domain specificity of affective and motivational constructs). Therefore, in the present research, we focused on the domain of mathematics as a prototypical and highly important scholastic domain.

Third, there is agreement that interest should be conceptualized as a multicomponent construct. Phenomenologically, interest includes both affective and cognitive components (Krapp, 2000; Renninger, 2000; Schiefele, 1991). The experience of interest typically involves positive emotions accompanying task engagement (e.g., enjoying working on arithmetic problems or being curious about the solution to problems); attributing value to a topic or activity (e.g., in terms of the subjective importance of arithmetic problems); possessing knowledge and feeling subjectively competent in the respective domain; and "thirst for knowledge," that is, the desire to learn more about the domain (Ainley, 2006; Hidi, 2000; Prenzel, 1992). In addition, interest often manifests itself in motivational energization and in repeated and autonomously chosen engagement with a topic or activity (Barron, 2006; Schiefele, 1998; Silvia, 2006). The present research also adopts a conceptualization of interest as comprising multiple affective, cognitive, and behavioral components.

\section{The Development of Interest}

In the current literature on interest development, two different perspectives on the phenomenon of development have been taken, one being across- and the other one being more within-person oriented (see also Krapp \& Lewalter, 2001). Taking an acrosspersons perspective on interest development, researchers typically explore how average interest scores change over time, depending on age. Taking a within-person perspective on interest development, researchers typically address what happens within persons during the interaction with an object of interest, independent of age. As mentioned above, a key finding from across-persons approaches to interest development is that there are considerable quantitative declines of students' self-reported levels of interest over the school years. These interest losses are observable in several different academic domains but are particularly pronounced in mathematics and science (Eccles et al., 1983; Eccles et al., 1984; Eccles et al., 1989; Gottfried et al., 2001; Köller, et al., 2001; Spinath \& Steinmayr, 2008). More specifically, recent studies have shown that this downward trend is curvilinear, with stronger declines during earlier years and a leveling off of interest toward late adolescence (Fredricks \& Eccles, 2002; Frenzel et al., 2010; Jacobs et al., 2002; Watt, 2004).

By contrast, researchers who take a within-person perspective on interest development typically focus on qualitatively different phases of interest, differentiating between early phases of a person-object interaction where interest is only "triggered," and later phases where interest becomes "well-developed” (e.g., Hidi \& Renninger, 2006; Lipstein \& Renninger, 2007; Renninger, 2000, 2009). The key finding within this approach is that the phase of interest development an individual is in makes an important difference. It has consistently been shown that students in different phases of interest vary considerably with respect to a wide array of variables relating to achievement behaviors (Durik \& Harackiewicz, 2007; Katz, Assor, Kanat-Maymon, \& Bereby-Meyer, 2006; Krapp \& Lewalter, 2001; Lipstein \& Renninger, 2007; Nolen, 2007; Renninger, Ewen, \& Lasher, 2002; Renninger \& Hidi, 2002; Renninger \& Leckrone, 1991; Tsai, Kunter, Lüdtke, Trautwein, \& Ryan, 2008).

Findings of these two perspectives clearly converge, particularly with respect to the adolescent student population. The low average levels of interest among adolescents as described in across-persons oriented studies correspond with the fact that in most withinperson oriented studies, only very few students of this age can be identified as being in a phase of well-developed interest. For example, only four of 178 students could be labeled as having a well-developed interest in writing in Lipstein and Renninger's (2007) study.

In the present research, we attempted to further integrate ideas from these two perspectives of interest development. We essentially used an across-persons approach, addressing trends in the construct of interest that can be found among adolescents, on average. Specifically, we concentrated on ages 10 years to 15 years (5th through 9th grades). At the same time, we focused on an issue typically addressed by within-person approaches to interest development, namely, the idea that there may be qualitative differences within the construct of interest over time. More specifically, we hypothesized that there are age-related shifts in students' concepts of what it means to be interested.

An important resource for generating hypotheses on such shifts in subjective concepts of interest is Hidi and Renninger's fourphase model of interest development (Hidi \& Renninger, 2006; see also Lipstein \& Renninger, 2007; Renninger, 2009, 2010). This model is one of the most recent and elaborated models on interest development taking a within-person perspective. In their model, Hidi and Renninger (2006) make explicit propositions about how the construct of interest is constituted in the different phases. Therefore, the model was particularly informative for our research question. Specifically, Hidi and Renninger argued that interest is predominantly composed of positive feelings and focused attention 
in the first phase. In the second phase, value becomes more important. In the third phase, knowledge and reengagement in the content domain gain importance, and in the fourth phase, reengagement becomes more and more self-generated. Studies supporting Hidi and Renninger's propositions typically were casebased, focusing on few individuals (Lipstein \& Renninger, 2007; Nolen, 2007; Renninger, 2010), or they involved short-term inquiry methods for studying the dynamic of interest and learning, such as online monitoring of student behaviors and experiences during a learning task (e.g., Ainley \& Hidi, 2002).

In summary, there is evidence that there are qualitatively different phases of interest when addressed from a within-person perspective, with a shift from predominantly affect-laden phases to phases where the cognitive components of interest play a more prominent role. We hypothesized that similar shifts should also exist with respect to age-related changes in students' subjective concepts of the construct of interest. However, evidence regarding such qualitative changes across persons, using sample-based designs and spanning longer timespans, was lacking to date.

We applied latent variable modeling and cognitive validation techniques to test this proposition. Both of these methodological approaches were used in nonstandard ways. Below, we briefly present these methodologies and explain how we adapted them to serve our purposes.

\section{Using Latent Variable Modeling and Tests of Measurement Invariance to Examine the Existence of Qualitative Change}

Typically, latent variable modeling is used to confirm a hypothesized structure among several items (confirmatory factor analysis) and to analyze relationships among latent variables (structural equation modeling). However, this method can also be used to analyze whether a hypothesized structure of a construct is stable across groups or over measurement occasions. Such analyses are referred to as tests of measurement invariance (see, e.g., Chan, 1998; Little, 1997; Meredith, 1993; Steenkamp \& Baumgartner, 1998; Vandenberg \& Lance, 2000).

In the present context, we used tests of measurement invariance to explore our hypothesis that the construct of interest undergoes structural changes during adolescence. To this end, we reanalyzed the data from a large longitudinal study where mathematics interest was assessed with six items across five consecutive school years (Grades 5 through 9, Frenzel et al., 2010). If our assumption of age-related structural changes within the construct of interest were true, then the coefficients depicting the structure of the latent variable of interest would differ across the assessments.

Remarkably, the classical repeated-measures design, which was typically used in studies examining interest development from a between-person perspective, implicitly assumes that the internal structure of the construct remains identical over time (as practiced, e.g., by Fredricks \& Eccles, 2002; Frenzel et al., 2010; Gottfried et al., 2001; Jacobs et al., 2002; Köller, et al., 2001; Spinath \& Steinmayr, 2008; Watt, 2004). However, we know of no study that examined whether the assumption of measurement invariance of interest is tenable across several years (see also Renninger \& Hidi, 2011).

\section{Using Cognitive Validation to Examine the Nature of Qualitative Change}

Cognitive validation emerged from research on cognitive aspects of achievement tests and survey methodology (e.g., Bowen, Bowen, \& Wooley, 2004; Forsyth \& Lessler, 1991; Karabenick et al., 2007; Woolley, Bowen, \& Bowen, 2004, 2006). Typically, this method is used to explore whether the research-based conceptualization of a certain construct as measured by several items is concordant with how a target population understands these items. To test this, respondents' cognitive associations prompted by the given items and their explanations concerning which answer they would choose on a given answer scale (and why) are analyzed. If these associations correspond with what the researchers intended to measure with the given items, the items are considered cognitively valid. Another way to use cognitive validation techniques is to apply them to the question of qualitative change of item interpretation across the developmental continuum (Karabenick et al., 2007).

In the present research, we made use of cognitive validation techniques to test our hypothesis of structural change within the construct of interest. Specifically, we examined whether students' subjective understanding of the construct of interest changes from predominantly affect-laden concepts in early adolescence to more cognitively oriented concepts. To this end, we interviewed 5th versus 9th graders about their understanding of the six items assessing mathematics interest that were used in the longitudinal data set of Study 1. We expected that participants' cognitive associations prompted by these items would differ between 5th versus 9th graders. To our knowledge, no studies on qualitative developmental shifts in concepts of interest have yet been undertaken.

\section{Aims and Hypotheses of the Present Research}

As noted, there is ample evidence regarding the considerable downward trajectories of academic interests and values in adolescence, particularly in the domain of mathematics. The key goal of the present research was to look beyond mere quantitative declines by examining qualitative changes of interest across adolescence. Our research was guided by the following hypotheses:

Hypothesis 1: The construct of mathematics interest undergoes structural changes during adolescence, as indicated by a lack of measurement invariance of self-reported interest over time (i.e., lack of invariance of intercepts, structural weights, and error variances).

Hypothesis 2: There is a shift from subjective concepts of interest that are more affect-laden in early adolescence to concepts that are more cognitively oriented later on, as indicated by age differences in spontaneous associations with given self-report items on mathematics interest.

Both hypotheses were tested for the developmental period from Grades 5 to 9 . Latent variable modeling was used to test Hypothesis 1 (lack of measurement invariance), and cognitive validation interviews were used to test Hypothesis 2 (shift from affective to cognitive concepts of interest). 


\section{Study 1}

This study was designed to test our first hypothesis. Reanalyzing a data set used by Frenzel et al. (2010), we employed a latent variable approach representing interest with multiple indicators at consecutive assessments. This made it possible to reveal whether qualitative changes of the construct of interest exist, as indicated by a lack of measurement invariance of interest in mathematics over time.

\section{Method}

Sample and procedure. Data from $N=3,193$ students ( $51 \%$ female, $49 \%$ male) were included in the analysis. These data were collected in the context of a large-scale longitudinal project examining students' learning in mathematics (Project for the Analysis of Learning and Achievement in Mathematics, PALMA, see Frenzel et al., 2010; Pekrun et al., 2007). For our analyses, student data from repeated measures starting in 5th grade and continuing to 9 th grade were used. The German Data Processing Center (DPC) of the International Association for the Evaluation of Educational Achievement (IEA) was responsible for obtaining the student sample and organizing assessments. Students from the PALMA sample came from a wide range of socioeconomic backgrounds, and from all three school tracks of the German state school system (see Pekrun et al., 2007, for a detailed description of the PALMA study). In the PALMA longitudinal study, intact classrooms were sampled in Grade 5 and followed in annual assessments over the subsequent school years. All schools and classes that were invited to participate in the study agreed to do so. For individual students, parental permission was required for participation and was solicited before the first administration. Parental consent rates were very high (average 97\% across years). Whenever class composition was reorganized across annual assessments (e.g., because some courses were offered as electives, such as foreign language courses), students who had not yet participated in the study but who became members of PALMA classrooms were added to the sample. As a result, despite study attrition, the number of students participating increased rather than decreased in most of the years $(2,023,2,016,2,302,2,308$, and 2,377 students participated in Grades 5, 6, 7, 8, and 9, respectively). In total, 3,193 students participated at least once; 2,564, 1,670, and 1,079 students participated at least 2, 3, and 4 times, respectively, and 776 students participated at each of the five assessment waves.

Measurement of mathematics interest. Student mathematics interest was assessed with the PALMA mathematics interest scale consisting of six items (see Appendix for a list of all items). The PALMA mathematics interest scale is based on items from the "Study Interest Questionnaire" (Schiefele, Krapp, Wild, \& Winteler, 1993), which were adapted to refer specifically to the subject of mathematics and to suit the target group of adolescent students. The scale assesses individual interest in the subject of mathematics, comprising of various components of the construct, including affective, cognitive, and behavioral aspects. Evidence for construct validity comes from this scale's consistent relationships with students' enjoyment of mathematics, as assessed with the Academic Emotions Questionnaire-Mathematics (Frenzel, Thrash, Pekrun, \& Goetz, 2007; Pekrun, Goetz, Frenzel, Barchfeld, \& Perry, 2011) and with parental as well as classroom values of mathematics
(Frenzel et al., 2010). Items were answered on a 5-point Likert scale ranging from 1 (strongly disagree) to 5 (strongly agree). The scale was internally consistent across the entire survey period (Cronbach's alphas were .87, .88, .86, .88, and .88 in Grades 5, 6, 7,8 , and 9).

Strategy of data analysis. All latent variable analyses were conducted using the software package Mplus 6.1 (Muthén \& Muthén, 1998-2008). We first created a baseline model that contained five latent variables for mathematics interest, one for each assessment. Each of the latent variables used the six items detailed above as indicators. These latent variables were all allowed to correlate. Errors of identical items over time were also allowed to correlate (correlated uniqueness model, e.g., Marsh, Byrne, \& Yeung, 1999). Model identification was achieved by setting the variances of each of the five latent interest variables to one and their latent means to 0 . Subsequently, we followed a stepwise procedure to establish measurement invariance across the five assessments, successively constraining item intercepts, structural weights, and error variances to equality (as recommended by, e.g., Chan, 1998; DeShon, 2004; Little, 1997; Meredith, 1993; Raykov, 2004; Steenkamp \& Baumgartner, 1998; Vandenberg \& Lance, 2000).

To assess overall model fit, we examined the $\chi^{2} / d f$ ratio and a range of practical fit indexes, including the comparative fit index (CFI), the root-mean-square error of approximation (RMSEA), the standardized root-mean-square residual (SRMR), and gamma hat (GH). We used the cutoff values recommended by $\mathrm{Hu}$ and Bentler (1999), whereby values $\geq .95$ for CFI and GH, $\leq .06$ for the RMSEA, and $\leq .08$ for the SRMR indicate a good model fit. We placed more emphasis on the practical fit indexes since the chisquare test has been shown to be overly sensitive to sample size, which in our case was very large (Marsh, Balla, \& McDonald, 1988).

To decide about the significance of loss of fit when setting item intercepts, structural weights, and error variances to equality over time, we used the likelihood ratio test assessing the significance of $\Delta \chi^{2} / \Delta d f$ for nested models with increasing measurement invariance constraints, and we inspected practical fit indexes. Following recommendations by Chen (2007) and Cheung and Rensvold (2002), we assumed that a change of $\geq .010$ in CFI, of $\geq .015$ in RMSEA, of $\geq .025$ in SRMR, and of $\geq .001$ for $\Delta \mathrm{GH}$ would indicate noninvariance of structural weights and that a change of $\geq .010$ in CFI, of $\geq .015$ in RMSEA, of $\geq .005$ in SRMR, and of $\geq .001$ for $\Delta \mathrm{GH}$ would indicate noninvariance of item intercepts and error variances. Again, we placed more emphasis on the practical fit indexes since the likelihood ratio test has also been shown to be rather sensitive to sample size.

\section{Results}

Table 1 shows the fit of the variants of our model with increasing degrees of measurement invariance. The unconstrained model (Model 1) had a very good fit (the significance of the $\chi^{2}$ statistic was attributable to the large sample size).

Constraining structural intercepts to equality resulted in a significant loss of fit (see Table 1, Model 2), compared with Model 1. the likelihood ratio test was significant $(p<.01)$, and in terms of the practical fit indexes, the loss of fit associated with the structural intercept constraint was largely unacceptable as well, as indicated 
Table 1

Measuring Mathematics Interest Across Grades 5-9: Model Fit When Constraining Different Measurement Coefficients to Invariance

\begin{tabular}{|c|c|c|c|c|}
\hline \multirow[b]{3}{*}{ Fit index } & \multicolumn{4}{|c|}{ Model } \\
\hline & 1 & 2 & 3 & 4 \\
\hline & Unconstrained & $\begin{array}{l}\text { Invariance of } \\
\text { item intercepts }\end{array}$ & $\begin{array}{l}\text { Invariance of item intercepts and } \\
\text { structural weights }\end{array}$ & $\begin{array}{l}\text { Invariance of item intercepts }+ \\
\text { structural weights }+ \text { error variances }\end{array}$ \\
\hline$x^{2}$ & 1,269 & 1,633 & 1,811 & 2,288 \\
\hline$\hat{d f}$ & 335 & 355 & 375 & 399 \\
\hline$p$ & $<.01$ & $<.01$ & $<.01$ & $<.01$ \\
\hline CFI & 0.973 & 0.963 & .959 & 0.946 \\
\hline GH & 0.992 & 0.990 & 0.988 & 0.984 \\
\hline SRMR & .026 & .033 & .039 & .045 \\
\hline RMSEA & .030 & .034 & .035 & .039 \\
\hline$\Delta \chi^{2} / \Delta d f$ & & $364 / 20^{*}$ & $178 / 20^{*}$ & $477 / 24^{*}$ \\
\hline$\Delta \hat{\mathrm{CFI}}$ & & $.010^{a}$ & .004 & $.013^{\mathrm{a}}$ \\
\hline$\Delta \mathrm{GH}$ & & $.002^{\mathrm{a}}$ & $.002^{\mathrm{a}}$ & $.004^{\mathrm{a}}$ \\
\hline$\triangle \mathrm{SRMR}$ & & $.007^{\mathrm{a}}$ & .006 & $.006^{\mathrm{a}}$ \\
\hline$\triangle$ RMSEA & & .004 & .001 & .004 \\
\hline
\end{tabular}

Note. All $\Delta \mathrm{s}$ shown refer to the previous model; that is, $\Delta \mathrm{s}$ for Model 2 are in reference to Model $1 ; \Delta \mathrm{s}$ for Model 3 are in reference to Model 2 , and so on. $\mathrm{CFI}=$ comparative fit index; $\mathrm{GH}=$ gamma hat; SRMR = standardized root-mean-square residual; RMSEA = root-mean-square error of approximation.

"Loss of fit indicating noninvariance according to Chen's (2007) and Cheung and Rensvold's (2002) cut-off criteria.

${ }^{*} p<.01$ (loss of fit statistically significant).

by the recommended cutoff criteria: In Model 2, compared with Model 1, the CFI, SRMR, and GH increased by .012, .010, and .002 , respectively. The increase of the RMSEA was the only one that could be considered tolerable. Additionally constraining structural weights of scale items to equality over time (see Table 1, Model 3) resulted in an additional loss of fit, although this additional loss was less serious. The likelihood ratio test was significant, and the loss of fit as indicated by $\Delta \mathrm{GH}$ was beyond the recommended boundary. The loss of fit in terms of $\triangle \mathrm{CFI}$, $\triangle$ SRMR, and $\triangle$ RMSEA was tenable. Finally, additionally constraining error variances to equality again resulted in a significant incremental loss of fit (see Table 1, Model 4). Compared with Model 3, the invariance constraint for the error variances resulted in a significant increase of the chi-square statistic relative to the increase in degrees of freedom $(p<.01)$, and CFI, SRMR, and GH indicated an incremental loss of fit beyond the recommended acceptable boundaries, compared with Model 3. Again, only the RMSEA indicated that the additional loss of fit was tenable. Overall, these results show that measurement invariance could not be established for the construct of interest as assessed longitudinally from Grades 5 through 9.

\section{Discussion}

Exploring the development of individual interest from an across-persons perspective, this study reanalyzed a data set pertaining to the development of interest in mathematics from Grades 5 to 9 (Frenzel et al., 2010) ${ }^{1}$ using a latent variable approach. In earlier studies, including Frenzel and colleagues' research, manifest variable approaches were used, such as classical analysis of variance or growth curve analyses based on manifest variables (Eccles et al., 1989; Fredricks \& Eccles, 2002; Gottfried et al., 2001; Jacobs et al., 2002; Köller, et al., 2001; Watt, 2004; Wigfield et al., 1991). Through the latent variable approach, we were able to test whether the measurement of mathematics interest could be considered invariant across the years of adolescence-an implicitly made, yet untested, assumption in classical manifest variable approaches. This allowed us to gain insight into the existence of qualitative changes in the construct of interest during the adolescent years.

Overall, our findings showed that across Grades 5 through 9, measurement invariance could not be established for the assessment of mathematics interest with the six items employed in this study. The changes in structural weights were relatively small in size, and the decreases in model fit associated with setting structural weights to equality fluctuated around the recommended boundaries (Chen, 2007; Cheung \& Rensvold, 2002). By contrast, item intercepts and error variances clearly varied over the years, as indicated by a loss of fit when constraining these parameters to equality over time.

Overall, these findings provide support for our first hypothesis. The existence of significant variability in the measurement coefficients depicting the structure of the latent variable of interest across assessments provides evidence that the construct changes structurally over time. However, these findings do not allow more specific inferences regarding the nature of these changes. Therefore, to gain a deeper understanding of qualitative shifts in the

\footnotetext{
' A key finding of this earlier study was that there is a curvilinear decline of mathematics interest across the observed developmental period, as mentioned earlier. The size and shape of this decline were not addressed in the present analyses. Readers interested in details regarding the quantitative decline of mathematics interest in the data used in the present study are directed to Frenzel et al. (2010).
} 
construct of interest across adolescence, we examined students' subjective concepts of this construct in Study 2.

\section{Study 2}

Study 2 aimed to explore changes in adolescent students' concepts of interest as triggered by the six self-report items employed in Study 1 in more detail. To this end, we used cognitive validation interviews. The method of cognitive validation involves a comparison of the participants' associations with given items and the researchers' intended conceptualization of the given construct. If both correspond, items are considered cognitively valid. Therefore, a key first step involved defining a priori which statements by the participants would be counted as adequately congruent with our conceptualization of the construct of interest. As detailed above, and in line with previous research, in the present research, we understand interest as comprising multiple affective and cognitive components (Ainley, 2006; Barron, 2006; Hidi, 2000; Krapp, 2000; Prenzel, 1992; Renninger, 2000; Schiefele, 1998; Silvia, 2006). Therefore, we defined a priori that participants' statements would be accepted as valid associations with the construct of interest if they fell among the following categories: (a) experiencing positive emotions during task engagement, (b) attaching values to a content or activity, (c) feeling competent in the respective domain, and (d) possessing thirst for knowledge, that is, the desire to learn more about the domain. In addition, since the motivational and behavioral consequences of interest are viewed as important constituents of the construct, we included statements referring to (e) energization to engage with a content or activity, (f) autonomy and self-direction in deciding to engage, and (g) resulting behavioral engagement as valid indicators of students' interest.

First of all, we expected that there would be an adequate degree of correspondence between both younger (5th grade) and older (9th grade) participants' statements, with these categories representing our a priori understanding of the construct of interest. Second, and more important, in line with our major research question, we hypothesized that the relative importance of these different components comprising the construct of interest would undergo a change across adolescence. Adapting propositions from Hidi and Renninger's (2006) four-phase model of interest development, we expected interest to be predominantly associated with positive emotional experiences during earlier phases of interest development and, correspondingly, among younger respondents. Also in line with Hidi and Renninger's suggestions for the conceptualization of interest in later phases, we expected that cognitive components (competence beliefs and thirst for knowledge) and autonomous engagement should gain more importance in older students' concepts of interest.

The following example illustrates these ideas regarding shifts in interest profiles across age. When answering the item, "I am interested in mathematics," respondents need to (a) interpret the content of the item; (b) retrieve relevant information from their autobiographical memory, such as thoughts and feelings related to the item; and (c) select the response option that is congruent with the information retrieved from memory (Karabenick et al., 2007; Woolley et al., 2004, 2006). We propose that younger students tend to predominantly consider emotional experiences as relevant for this item, whereas other components may not yet play an important role for them in association with the concept of interest.
A young student might think, for example, "Yes, I am interested in mathematics because it is fun to solve arithmetic problems and to work with a compass and protractor." In contrast, older students may attach more importance to the other components, such as knowledge and autonomous task choice in the respective domain. He or she may think, for example, "Yes, I am interested because I find myself always wanting to learn more about math," whereas younger adolescents may not even consider that continually wanting to increase one's knowledge in mathematics would be an important feature of being interested in this domain.

\section{Method}

\section{Participants and procedure.}

Sample. The sample included 70 students from Grade $5(n \mathrm{~s}=$ 21 girls \& 14 boys; mean age 10.4 years, $S D=0.60$ ) and Grade $9(n \mathrm{~s}=17$ girls $\& 18$ boys; mean age $=14.7$ years, $S D=0.60)$. Students were recruited from five different secondary schools (Gymnasium) and were randomly selected from the 5th and 9th grade classes of these schools. Participation was voluntary, and written parental consent was obtained in order for students to participate.

Cognitive validation interview. The interviews took place during regular class hours. Participants were interviewed individually by trained interviewers in separate rooms provided by the schools. Before the interview started, participants were asked to give verbal consent to the recording of the interview; in addition, students' gender and grade level were noted, students were informed about the interview procedure, and they were assured that their answers would remain confidential. In order to explore students' concepts of interest as triggered by the six self-report items employed in Study 1, students were shown each of the six items consecutively on a laptop using an MS Office 2003 PowerPoint slide show.

According to the recommended guidelines for cognitive validation (Bowen et al., 2004; Karabenick et al., 2007), the interview followed a four-step procedure for asking students about their thoughts on each of the six items. The four steps included the following requests and questions: 1 . "Please read the question out loud," 2. "What is this question trying to find out from you?" 3. "Which answer would you chose as the right answer for you?" and 4. "Can you explain to me why you chose that answer?" Prior to Step 1, the corresponding item was displayed on the laptop screen by the interviewer. Prior to Step 3, the Likert rating scale for answering the item ranging from 1 (strongly disagree) to 5 (strongly agree) was added to the screen. For Steps 2 and 4, item-specific follow-up probes were used by the interviewers in case participants experienced problems reporting about their thoughts (e.g., for Item 1, Step 2, follow-up questions were "What does it mean to be interested?" and "What is it like when someone is interested?" For Step 4, the follow-up question was "Can you give me an example?"). This procedure was repeated for all six interest items. At the end of the interview, students' self-reported mathematics grade on their last class exam was recorded. The interviews lasted on average 8 min and $39 \mathrm{~s}$. As a thank you for their participation, students received a small gift at the end of the interview.

Coding procedure. The interviews were digitally recorded and later transcribed verbatim. Transcripts were coded using the 
computer program MAXQDA 2007 (Kuckartz, 1995-2007). As detailed earlier, in line with current definitions of interest, student statements were coded if they fell among the following categories: (a) positive emotional experiences, (b) valuing the respective domain, (c) subjective competence in the respective domain, (d) thirst for knowledge, (e) energization to engage in the domain, (f) autonomous task choice in the respective domain, and $(\mathrm{g})$ repeated behavioral engagement in the domain. These seven categories were clearly distinguishable for the raters, and all statements could be sorted into these categories. Table 2 provides typical marker words representing each category, along with sample statements for each category.

If mentioned several times within the responses to an item, identical statements were coded only once (e.g., "It is fun to solve brain teasers" and "It is fun to work with a compass and protractor" were coded only once as emotional experience when coding Item 1). Codes for semantically different statements pertaining to one category were summed across the entire interview (e.g., "I believe I am a good student in math" and "It is easy for me to do math" were coded as two statements in the category of subjective competence). Negatively framed statements were coded in the respective category; for example, "Because I am simply not good at mathematics" was coded in the category of feelings of subjective competence. Statements were not coded if they contained exactly the same key words as used in the respective item (e.g., curiosity or the adjective curious in Item 5, "After a math class, I am often curious about what we are going to do in the next lesson").

Three independent trained raters cross-coded six of the interviews to obtain an estimate of interrater reliability. Interrater agreement in terms of Cohen's kappa (Cohen, 1960) was high, with values .92, .84, and .85 for raters $1 / 2,1 / 3$, and $2 / 3$, respectively.

Control variables. We controlled for gender, mathematics achievement, and verbal fluency in our analyses. As a proxy for mathematics achievement, we used students' self-reported grades on their last math exam. As a proxy for verbal fluency, we used the total number of codeable statements in the entire interview for each student. By entering control variables, we sought to ensure that any group differences were not mere epiphenomena of these variables.

\section{Results}

Preliminary analyses.

Descriptive statistics for total number of codeable statements. Overall, students made $M=21.54(S D=5.67)$ codeable statements during the entire interview. There were no significant age or gender differences for this total number of codeable statements $(M \mathrm{~s}=20.74 \& 22.34, S D \mathrm{~s}=5.40 \& 5.90$, for Grades 5 and 9 , respectively; $t=1.18, n s ; M s=22.34 \& 22.63, S D s=5.90$ $\& 5.86$, for female and male students, respectively; $t=1.77, n s)$.

Cognitive validity of items in Grades 5 and 9. We explored whether items could be considered cognitively valid for both age groups, that is, whether students' statements regarding the items were concordant with our theoretically defined understanding of the construct of interest. An item was considered cognitively valid for a participant if his or her answers could be coded into at least one of the seven theoretically established categories. Items 1 and 4 yielded valid answers from all participants within each age group. Items 2 and 3 were each misunderstood by one single student in grade 9. Responses to Item 6 were invalid for one single student within each of the two age groups. Two students in Grade 5 and one student in Grade 9 seem to have misunderstood Item 4, as they did not associate it with any of the components of interest. Not a single student misunderstood more than one item. In sum, we concluded that all of the items were cognitively valid in terms of our component construct definition of interest, as indicated by the high percentage of students interpreting each of the items in terms of at least one of the seven component categories. This was the case both for younger (Grade 5) and older (Grade 9) adolescents.

Profiles of interest components across items. Another interesting preliminary result involves the number of statements students made per item referring to the various interest components. These data allow inferences about item specificities, that is, the profile of components that were predominantly associated with each of the items. Table 3 shows these data for the entire student sample, as well as separately for the two age groups. Looking at the three components associated most often with each of the items, the following pattern emerged. For Item 1, students from both age groups named emotional components most often, followed by feelings of competence and behavioral engagement (with competence being more pronounced among 9th graders). For Items 2 and 3 , students from both age groups also named emotional experiences most often, followed by behavioral engagement and autonomy. Item 4 also most often triggered statements referring to affect and behavioral engagement but triggered statements referring to thirst for knowledge as well. For Item 5, students again named emotional experiences most often, followed by statements referring to thirst for knowledge and energization. Notably, the predominance of statements referring to emotional experiences rela-

Table 2

Categories for Coding Student Statements in the Cognitive Validation Interview: Marker Words and Sample Statements

\begin{tabular}{|c|c|c|}
\hline Category & Marker words & Sample statement \\
\hline Emotional experience & enjoy, fun, like, love & "I really like mathematics" (ID35) \\
\hline Value of mathematics & prefer, useful & "Math can be useful for solving everyday problems." (ID38) \\
\hline Subjective competence & (good) grades & "If someone is good at math." (ID36) \\
\hline Thirst for knowledge & want to/desire to know & "That someone wants to know the solution to a math problem." (ID26) \\
\hline Energization & want to, avoid & "That I want do my math homework before I do any other task." (ID40) \\
\hline Autonomy & hobby, choose, voluntary & "Because I voluntarily do math in my spare time." (ID22) \\
\hline Behavioral engagement & do, engage in, spend time with & "For example, to actively engage in topics that are related to math." (ID22) \\
\hline
\end{tabular}

Note. Information in parentheses represents the students' interview identification (ID) number. 
Table 3

Item Profiles: Mean Number of Statements per Category and Item Within and Across Age Groups

\begin{tabular}{|c|c|c|c|c|c|c|c|}
\hline \multirow[b]{2}{*}{ Item } & \multicolumn{7}{|c|}{ Interest component } \\
\hline & $\begin{array}{l}\text { Emotional } \\
\text { experience }\end{array}$ & $\begin{array}{l}\text { Value of } \\
\text { math }\end{array}$ & $\begin{array}{c}\text { Subjective } \\
\text { competence }\end{array}$ & $\begin{array}{l}\text { Thirst for } \\
\text { knowledge }\end{array}$ & Energization & Autonomy & $\begin{array}{c}\text { Behavioral } \\
\text { engagement }\end{array}$ \\
\hline & & & & Total & & & \\
\hline Item 1 & 1.93 & 0.31 & 0.79 & 0.40 & 0.07 & 0.26 & 1.01 \\
\hline Item 2 & 1.37 & 0.07 & 0.10 & 0.07 & 0.09 & 0.66 & 1.30 \\
\hline Item 3 & 1.63 & 0.54 & 0.29 & 0.10 & 0.10 & 0.70 & 1.06 \\
\hline Item 4 & 1.00 & 0.29 & 0.34 & 0.46 & 0.06 & 0.07 & 0.56 \\
\hline Item 5 & 1.47 & 0.16 & 0.17 & 0.53 & 0.20 & 0.04 & 0.13 \\
\hline \multirow[t]{2}{*}{ Item 6} & 0.53 & 0.10 & 0.30 & 1.24 & 0.23 & 0.43 & 0.40 \\
\hline & \multicolumn{7}{|c|}{ Grade 5} \\
\hline Item 1 & 2.17 & 0.37 & 0.74 & 0.49 & 0.06 & 0.06 & 0.66 \\
\hline Item 2 & 1.69 & 0.09 & 0.06 & 0.00 & 0.09 & 0.51 & 1.31 \\
\hline Item 3 & 1.57 & 0.54 & 0.17 & 0.09 & 0.11 & 0.69 & 0.97 \\
\hline Item 4 & 1.23 & 0.26 & 0.31 & 0.40 & 0.09 & 0.09 & 0.51 \\
\hline Item 5 & 1.46 & 0.17 & 0.09 & 0.37 & 0.26 & 0.03 & 0.09 \\
\hline \multirow[t]{2}{*}{ Item 6} & 0.60 & 0.11 & 0.20 & 1.03 & 0.29 & 0.34 & 0.40 \\
\hline & \multicolumn{7}{|c|}{ Grade 9} \\
\hline Item 1 & 1.69 & 0.26 & 0.83 & 0.31 & 0.09 & 0.46 & 1.37 \\
\hline Item 2 & 1.06 & 0.06 & 0.14 & 0.14 & 0.09 & 0.8 & 1.29 \\
\hline Item 3 & 1.69 & 0.54 & 0.40 & 0.11 & 0.09 & 0.71 & 1.14 \\
\hline Item 4 & 0.77 & 0.31 & 0.37 & 0.51 & 0.03 & 0.06 & 0.60 \\
\hline Item 5 & 1.49 & 0.14 & 0.26 & 0.69 & 0.14 & 0.06 & 0.17 \\
\hline Item 6 & 0.46 & 0.09 & 0.40 & 1.46 & 0.17 & 0.51 & 0.40 \\
\hline
\end{tabular}

tive to all other statements was most pronounced for Item 5, compared with all other items. Item 6 was the only item that was not so strongly associated with emotional experiences. Rather, for Item 6, students named most often statements on thirst for knowledge, followed by emotional experiences for younger students and autonomy for older students.

Age differences in concepts of interest. In this analysis, age group served as the independent variable, and frequencies of statements in the seven categories across the entire interview served as dependent variables. The dependent variable thus had the nature of count data. Accordingly, we used Poisson regression (e.g., Cameron \& Trivedi, 1998; Lawless, 1987) to analyze group differences. In a second step, we entered gender, mathematics achievement, and verbal fluency as covariates.

Table 4 shows how students' statements were distributed across the seven categories in terms of mean number of statements per student in the entire interview, both for the total sample and separately for 5 th versus 9 th graders (see Table 4, columns 1-3). In the total sample, statements referring to emotional experiences had the highest frequency ( $37 \%$ of all statements), followed by statements referring to behavioral engagement in the domain of mathematics ( $21 \%$ of all statements). Statements referring to energization were named least frequently, namely, less than once per interview across all students (3.4\% of all statements).

Table 4

Construct Profiles: Interest Components in 5th and 9th Graders

\begin{tabular}{|c|c|c|c|c|c|c|c|c|c|}
\hline \multirow[b]{2}{*}{ Component } & \multicolumn{3}{|c|}{$\begin{array}{l}\text { Mean number of statements in total } \\
\text { interview \& percentage relative to } \\
\text { total in parentheses }\end{array}$} & \multicolumn{2}{|c|}{$\begin{array}{l}\text { Mean comparison } \\
\text { without covariates }\end{array}$} & \multicolumn{2}{|c|}{$\begin{array}{l}\text { Estimated mean } \\
\text { number of statements } \\
\text { in total interview } \\
\text { based on Poisson } \\
\text { regression with } \\
\text { covariates }\end{array}$} & \multicolumn{2}{|c|}{$\begin{array}{l}\text { Mean comparison } \\
\text { with covariates }\end{array}$} \\
\hline & Total & Grade 5 & Grade 9 & Wald $x^{2}$ & $p$ & Grade 5 & Grade 9 & Wald $\chi^{2}$ & $p$ \\
\hline Emotional experience & $7.93(36.8)$ & $8.71(42.0)$ & $7.14(32.0)$ & 2396.0 & $<.01$ & 9.00 & 6.44 & 12.0 & $<.01$ \\
\hline Value of math & $1.47(6.8)$ & $1.54(7.4)$ & $1.40(6.3)$ & 15.7 & $<.01$ & 1.34 & 1.34 & 0.0 & .99 \\
\hline Subjective competence & $1.99(9.2)$ & $1.57(7.6)$ & $2.40(10.7)$ & 75.6 & $<.01$ & 1.73 & 1.74 & 0.0 & .96 \\
\hline Thirst for knowledge & $2.80(13.0)$ & $2.37(11.4)$ & $3.23(14.5)$ & 217.1 & $<.01$ & 2.37 & 3.15 & 3.0 & .08 \\
\hline Energization & $0.74(3.4)$ & $0.89(4.3)$ & $0.60(2.7)$ & 5.9 & .051 & 0.86 & 0.53 & 2.3 & .13 \\
\hline Autonomy & $2.16(10.0)$ & $1.71(8.2)$ & $2.60(11.6)$ & 100.5 & $<.01$ & 1.61 & 2.61 & 6.8 & $<.01$ \\
\hline Behavioral engagement & $4.46(20.7)$ & $3.94(19.0)$ & $4.97(22.2)$ & 707.2 & $<.01$ & 3.66 & 4.92 & 5.3 & $<.05$ \\
\hline
\end{tabular}

Note. Gender, self-reported mathematics grade, and total number of coded statements per student were used as covariates. 
Table 4 depicts the results of the age group comparisons. Without covariates the mean comparisons were all statistically significant $(p<.01)$, with the exception of the category energization. After introducing gender, mathematics grade, and total number of coded statements in the interview as covariates, significant or marginally significant age differences remained for the following interest components: emotional experiences $(p<.01)$, thirst for knowledge (marginally significant, $p=.08$ ), autonomy $(p<.01)$, and behavioral engagement $(p<.05)$. All of these effects were medium in size. Emotional experiences were clearly mentioned more frequently by 5 th graders than by 9 th graders $\left(\eta^{2}=.06\right)$. Thirst for knowledge was mentioned more frequently by 9 th graders $\left(\eta^{2}=.07\right)$, as were aspects of autonomous task choice within mathematics $\left(\eta^{2}=.08\right)$. Finally, Grade 9 students mentioned aspects of behavioral engagement more frequently than did 5th graders $\left(\eta^{2}=.05\right)$

\section{Discussion}

Study 2 was designed to explore differences in concepts of interest between adolescents of different age groups (Grade 5 vs. Grade 9). To this end, we conducted interviews with 5th and 9th graders, adapting the method of cognitive validation (e.g., Bowen et al., 2004; Forsyth \& Lessler, 1991; Karabenick et al., 2007; Woolley et al., 2004, 2006) to assess differences between younger and older adolescents' thoughts when confronted with interest scale items.

A preliminary finding was that the interest scale items used in the present research could be considered cognitively valid for adolescents from both age groups. In other words, the spontaneous associations produced by participants when reading the items, as well as their explanations for rating the degree to which they would endorse each of the items themselves, were concordant with current, research-based conceptualizations of interest. More specifically, in line with current conceptualizations, students of both age groups mentioned the following components of mathematics interest: positive emotional experiences when dealing with mathematics, values attached to the domain of mathematics, subjective competence in mathematics, thirst for knowledge in this domain, feeling energized to engage with mathematics, autonomous task choice, and repeated behavioral engagement in mathematics.

Furthermore, our analyses regarding item-specific profiles revealed that most of the items measure interest rather holistically. With the exception of Item 6, all of our items predominantly triggered associations with emotional experiences; however, all items also showed associations with each of the other components. The predominance of emotional experiences was particularly pronounced for Item 5, whereas Item 6 was predominantly associated with thirst for knowledge in both age groups.

As predicted, there were systematic changes in the frequencies of mentioning different components across age groups. In line with propositions extrapolated from Hidi and Renninger's (2006) model of interest development, adolescents' concepts became less affectladen with increasing age, and cognitive components became more important, especially so for thirst for knowledge. Furthermore, behavioral engagement and autonomous task choice was more important to older students. Contrary to expectations, there were no age differences regarding the importance of subjective competence in mathematics.
In interpreting these findings, one might alternatively argue that the two age groups differed in verbal skills. From this perspective, older adolescents might simply be better able to formulate their understanding of the construct, rather than truly having an altered concept of the construct. However, it is worth noting that our results were obtained while controlling for verbal fluency, operationalized in terms of total number of codeable statements within the interview. This suggests that the observed shifts were independent of any age-related increase of verbal skills. In addition, it is important to note that the observed shifts were not simply uniform trends. Rather, the importance of emotional experiences for participants' concepts of interest was less pronounced in older adolescents, compared with younger adolescents, while the importance of cognitive components of the construct (thirst for knowledge and autonomous task choice) was more pronounced for older adolescents.

\section{General Discussion}

The present research addressed a classic problem in developmental psychology, the issue of qualitative versus quantitative change over time. The two studies presented herein focused on a prominent motivational construct-academic interest and, more specifically, interest in mathematics. In this research, we did not intend to fuel the debate about quantitative versus qualitative change by arguing in favor of one and denouncing the other. Rather, we aimed to contribute to an integration of the two perspectives. Focusing on the construct of interest, our findings suggest that insight into qualitative shifts can complement what is known about quantitative change. More specifically, we hypothesized that the construct of interest undergoes qualitative change during adolescence in terms of a shift from affective to cognitive concepts of the construct. By so doing, we took an across-persons perspective on the development of interest, exploring potential changes in the construct of interest that apply, on average, across the adolescent student population. Our approach should be differentiated from a within-person perspective, which explores what happens within individuals during their interaction with an object of interest.

Our hypothesis that the construct of interest undergoes qualitative change during adolescence in terms of a shift from affective to cognitive concepts of the construct was inspired by one of the most recent and elaborated models on interest development rooted in a within-person perspective, namely, Hidi and Renninger's (2006) fourphase model of interest development. This model proposes that the development of interest involves qualitatively different phases, with affective components being predominant in earlier phases and cognitive components gaining importance in later phases.

Study 1 used strategies for testing measurement invariance that are embedded in a latent variable approach. Reanalyzing a large, longitudinal data set assessing mathematics interest from Grades 5 through 9 in Germany (Frenzel et al., 2010), the findings showed that interest as measured with self-report items could not be considered invariant across this developmental period, in line with Hypothesis 1. Specifically, item intercepts and error variances showed clear differences between the assessments. This can be interpreted as evidence that the construct structurally changes over time. If the structure of the construct had remained stable, then the 
psychometric properties of the assessments would have been statistically invariant over time.

Study 2 adapted the method of cognitive validation to test whether the change of interest across this age period was characterized by a shift from more affective to more cognitive concepts. Indeed, in line with Hypothesis 2, whereas 5th graders' associations with the given items were predominantly affective, 9 th graders named significantly more cognitive aspects. The following quotations from our interviews illustrate these findings. When asked what Item 1 ("I am interested in mathematics") meant in their own words, one 5th grader said, "well that you engage in it, and that you're not like, oh, not math class again ... and that you take your homework seriously and do it very exactly," and another Grade 5 student said, "uhhmm for example, that when you do math, you like doing it, and when you do math, you're happy about it ... and, uhhmm, when it is fun learning it and maybe you can remember it. And not being interested means that it is no fun at all. That you say, oh, no, I really don't feel like doing this now, because it is stupid or so." In contrast, a 9th grader said, "that someone has particular topics as a hobby, for example, like me, the computer, and doing programming. Or that you seek to do something really complicated related to that topic, for example, in math, to calculate something." Another Grade 9 student said, "that I like doing it and do it often, also in my leisure time." Clearly, the interview-based approach of this study proved valuable in gaining a deeper understanding of interest development during adolescence (see also Lipstein \& Renninger, 2007; Nolen, 2007; Renninger, 2009; Wigfield \& Cambria, 2010).

As such, our findings are in line with propositions extrapolated from Hidi and Renninger's (2006) model regarding shifts of this type during the emergence of well-developed individual interest from situationally triggered interest. To the best of our knowledge, the present research is the first showing that such qualitative shifts also occur as seen from an across-persons perspective on interest development, spanning several years. Our findings imply that younger students tend to predominantly associate positive emotional experiences with the phenomenon of being interested, whereas older students appear to become increasingly aware that being interested also involves the desire to learn more and autonomously choose to engage in the respective domain. Our data clearly document the existence of such structural changes in mathematics interest over this developmental span, even if they are only medium in size.

One important methodological implication of the present findings is that the method of cognitive validation, that is, the analysis of respondents' cognitive interpretation of the items of measurement instruments, can be useful for revealing shifts in the meaning of self-report measures across age groups. While the method of cognitive validation was initially developed to pretest newly developed items, specifically for their use with children (Bowen et al., 2004; Woolley et al., 2004, 2006), the technique is clearly well suited to reveal qualitative changes in item interpretation across the developmental continuum (Karabenick et al., 2007). Future studies should use this approach to analyze age-related changes in subjective concepts for other popular constructs, such as selfconcept, values, achievement emotions, or goals.

Another important methodological implication of the present findings concerns the problems involved in the absence of measurement invariance of constructs over time. Measurement theo- rists have long cautioned that this is a critical issue for implications drawn about development and change. In 1947, Thurstone pointed to the need to establish invariance of measurement. Still, in 2001, Meredith and Horn observed that

in most research it was simply assumed that if the same test was used in different samples or at different times with the same people, the same attribute was measured. Rarely was there any mention of the possibility that this might not be true (p. 205f).

The present findings provide evidence that the requirement of measurement invariance might in part be violated for the construct of interest and related motivational variables, which have attracted quite some research attention and have repeatedly been subject to longitudinal analysis (Eccles et al., 1983; Eccles et al., 1984; Eccles et al., 1989; Fredricks \& Eccles, 2002; Gottfried et al., 2001; Jacobs et al., 2002; Köller, et al., 2001; Spinath \& Steinmayr, 2008; Watt, 2004; Wigfield et al., 1991). We posit that attending to issues of measurement invariance is as relevant for developmental research as the widely accepted conviction that cross-sectional data should not be interpreted in terms of developmental change. We propose that sensitivity to this problem should be promoted, and issues of measurement invariance should be attended to when planning developmental studies. Our findings show that cognitive validation techniques may be suitable for exploring changes a construct may undergo over time. Future studies could employ this method to develop self-report instruments that can be used with different age groups, ensuring that items trigger the same kind of associations from participants of various age groups. Furthermore, we concur with recommendations that tests of measurement invariance should be treated as an imperative step in any study addressing quantitative change over time. If there are only a few instances of violation of measurement invariance, creating partial invariance models could be helpful (e.g., Byrne, Shavelson, \& Muthén, 1989; Meredith \& Horn, 2001). In case these recommendations are implemented in self-report studies, we are convinced that valid findings can be produced-even for complex constructs such as interest-despite the challenges posed by violations of measurement invariance requirements.

\section{Limitations, Directions for Future Research, and Practical Implications}

The present research has some limitations that should be kept in mind when interpreting the findings and that provide suggestions for future research. Specific limitations of Study 2 pertain to its crosssectional nature and its focus on students from the highest track (Gymnasium). Our inferences regarding age-related changes in concepts of mathematics interest might be restricted to this particular group of students. It would be desirable to replicate the study findings sampling students from various school types and using longitudinal designs by conducting cognitive validity interviews in several consecutive years with one identical longitudinal sample of participants.

Furthermore, both studies presented data based on students' self-report. It should be kept in mind that interest may include more than what people can report on and that we might not capture these more subtle, maybe nonverbalizable, facets of interest with our methodologies of survey (Study 1) and interview (Study 2). Future studies could use other perspectives (e.g., parents, peers) and alternative assessment approaches (such as behavioral traces 
or facial codes of emotions) to gain further insight into developmental phenomena of the construct of interest.

In addition, our findings address only one domain, age group and student subgroup under study. It would thus be desirable to replicate our findings within other academic domains, to extend them into nonacademic domains (e.g., interest in sports or music) or to general student interest. Exploring other age groups beyond the adolescent years, including younger participants as well as older participants (i.e., elementary school students and adults), would represent an intriguing avenue for future research. Finally, components may also vary in their relative importance for different subgroups of adolescents (such as, students from different school tracks), not only over time. This could be addressed in future studies.

Another important contribution of the present research was to identify a broad conceptualization of interest that is both in line with contemporary definitions of the construct and with students' understanding of the construct. However, it may be argued that the six-item scale we used to assess mathematics interest does not perfectly represent each of the seven components of interest as proposed in this conceptualization. It would be an intriguing avenue for future research if each of the seven components of interest as identified in our research were represented with at least two to three items and submitted to a longitudinal repeated-measures design as in Study 1. This would allow us to quantify the findings from our qualitative Study 2 in terms of the size of possible changes in the contribution that each of these subcomponents makes to the higher order factor of interest.

However, it is to be expected that more complex measures would be more susceptible to violations of measurement invariance across groups and time. Thus for the sake of quantifying the "true size" of interest changes across longer time spans, more complex measures would likely be rather unsuitable. As such, there may be a conflict between the goals of comprehensive conceptualization of constructs and methodological rigor in analyzing change or comparing groups. These two goals need careful considerations when planning developmental studies in general.

Finally, the present research has implications for how educators might trigger and then support learners to develop interest. Given the conceptual shifts in interpretations of the construct of interest across adolescence, it may be worthwhile to target age-specific profiles of the components of interest as a means of increasing interest. While research has shown that interventions directed at increasing students' interests are successful if they take into account which phase of interest an individual student is in (e.g., Durik \& Harackiewicz, 2007), age-specific interest intervention strategies do not seem to have been addressed in the context of promoting academic motivation (e.g., Hidi \& Harackiewicz, 2000). Our findings provide some insight into how such agespecific intervention strategies could be designed. For younger students, to whom affective experiences seem to play a major role in forming their interests, it is recommendable to provide positive emotional experiences. In contrast, for older students, cognitive aspects seem to play a more important role; thus, in order to instill their interests, it might be a successful strategy to appeal to autonomy and the desire to learn more about a domain. For the domain of mathematics, positive emotional experiences could, for example, be conveyed by offering real-life, exciting problems and by encouraging students to connect course materials to their lives (Hulleman \& Harackiewicz, 2009) or by inducing enthusiasm in students via displays of one's own math-related enjoyment (Frenzel, Goetz, Lüdtke, Pekrun, \& Sutton, 2009). Autonomy could be promoted by providing choices or by pointing out that several solutions to a math problem are possible (e.g., Reeve, Bolt, \& Cai, 1999). In addition, to appeal to thirst for knowledge, educators could emphasize yet unexplored mathematics problems or problems that have long been unsolved (such as the so-called Fermat's last theorem; see, e.g., Singh, 1997). In sum, attending to agerelated changes of constructs such as interest may generally prove worthwhile in order to help educators foster children's and adolescents' academic and motivational development.

\section{References}

Ainley, M. (2006). Connecting with learning: Motivation, affect and cognition in interest processes. Educational Psychology Review, 18, 391405. doi:10.1007/s10648-006-9033-0

Ainley, M., \& Hidi, S. (2002). Dynamic measures for studying interest and learning. In P. R. Pintrich \& M. L. Maehr (Eds.), Advances in motivation and achievement: New directions in measures and methods (Vol. 12, pp. 43-76). New York, NY: JAI.

Ainley, M., Hidi, S., \& Berndorff, D. (2002). Interest, learning and the psychological processes that mediate their relationship. Journal of Educational Psychology, 94, 545-561. doi:10.1037/0022-0663.94.3.545

Barron, B. (2006). Interest and self-sustained learning as catalysts of development: A Learning Ecology Perspective. Human Development, 49, 193-224. doi: $10.1159 / 000094368$

Baumert, J., \& Köller, O. (1998). Interest research in secondary level I: An overview. In L. Hoffmann, A. Krapp, K. A. Renninger, \& J. Baumert (Eds.), Interest and learning (pp. 241-256). Kiel, Germany: IPN.

Bong, M. (2001). Between- and within-domain relations of academic motivation among middle and high school students: Self-efficacy, task value and achievement goals. Journal of Educational Psychology, 93, 23-34. doi: 10.1037/0022-0663.93.1.23

Bowen, N. K., Bowen, G. L., \& Woolley, M. E. (2004). Constructing and validating assessment tools for school-based practitioners: The Elementary School Success Profile. In A. R. Roberts \& K. Y. Yeager (Eds.), Evidence-based practice manual: Research and outcome measures in health and human services (pp. 509-517). New York, NY: Oxford University Press.

Byrne, B. M., Shavelson, R. J., \& Muthén, B. (1989). Testing for the equivalence of factor covariance and mean structures: The issue of partial measurement invariance. Psychological Bulletin, 105, 456-466. doi:10.1037/0033-2909.105.3.456

Cameron, A. C., \& Trivedi, P. K. (1998). Regression analysis of count data. Cambridge, England: Cambridge University Press.

Chan, D. (1998). The conceptualization and analysis of change over time: An integrative approach multiple indicator latent growth modeling (MLGM) incorporating longitudinal mean and covariance structures analysis (LMACS) and multiple indicator latent growth modeling (MLGM). Organizational Research Methods, 1, 421-483. doi:10.1177/ 109442819814004

Chen, F. F. (2007). Sensitivity of goodness of fit indexes to lack of measurement invariance. Structural Equation Modeling, 14, 464-504. doi:10.1080/10705510701301834

Cheung, G. W., \& Rensvold, R. B. (2002). Evaluating goodness-of-fit indexes for testing measurement invariance. Structural Equation Modeling, 9, 233-255. doi:10.1207/S15328007SEM0902_5

Cohen, J. (1960). A coefficient of agreement for nominal scales. Educational and Psychological Measurement, 20, 37-46. doi:10.1177/ 001316446002000104

DeShon, R. P. (2004). Measures are not invariant across groups without error variance homogeneity. Psychology Science, 46, 137-149. 
Durik, A. M., \& Harackiewicz, J. M. (2007). Different strokes for different folks: How personal interest moderates the effects of situational factors on task interest. Journal of Educational Psychology, 99, 597-610. doi: 10.1037/0022-0663.99.3.597

Eccles, J. S., Adler, T. F., Futtermann, R., Goff, S. B., Kaczala, C. M., Meece, J. L., \& Midgley, C. (1983). Expectancies, values and academic behaviors. In J. T. Spence (Ed.), Achievement and achievement motives: Psychological and sociological approaches (pp. 75-145). San Francisco, CA: Freeman.

Eccles, J. S., Adler, T. F., \& Meece, J. L. (1984). Sex differences in achievement: A test of alternate theories. Journal of Personality and Social Psychology, 46, 26-43. doi:10.1037/0022-3514.46.1.26

Eccles, J. S., Wigfield, A., Flanagan, C., Miller, C., Reuman, D., \& Yee, D. (1989). Self-concept, domain values, and self-esteem: Relations and changes at early adolescence. Journal of Personality, 57, 283-310. doi:10.1111/j.1467-6494.1989.tb00484.x

Forsyth, B. H., \& Lessler, J. T. (1991). Cognitive laboratory methods: A taxonomy. In P. P. Biemer, R. M. Groves, L. E. Lyberg, N. A. Mathiowietz, \& S. Sudman (Eds.), Measurement errors in surveys (pp. 393 418). New York, NY: Wiley.

Fredricks, J. A., \& Eccles, J. S. (2002). Children's competence and value beliefs from childhood through adolescence: Growth trajectories in two male-sex-typed domains. Developmental Psychology, 38, 519-533. doi: 10.1037/0012-1649.38.4.519

Frenzel, A. C., Goetz, T., Lüdtke, O., Pekrun, R., \& Sutton, R. (2009). Emotional transmission in the classroom: Exploring the relationship between teacher and student enjoyment. Journal of Educational Psychology, 101, 705-716. doi:10.1037/a0014695

Frenzel, A. C., Goetz, T., Pekrun, R., \& Watt, H. M. G. (2010). Development of mathematics interest in adolescence: Influences of gender, family and school context. Journal of Research on Adolescence, 20, 507-537. doi:10.1111/j.1532-7795.2010.00645.x

Frenzel, A. C., Thrash, T. D., Pekrun, R., \& Goetz, T. (2007). Achievement emotions in Germany and China: A cross-cultural validation of the Academic Emotions Questionnaire-Mathematics. Journal of CrossCultural Psychology, 38, 302-309.

Goetz, T., Cronjaeger, H., Frenzel, A. C., Lüdtke, O., \& Hall, N. C. (2010). Academic self-concept and emotion relations: Domain specificity and age effects. Contemporary Educational Psychology, 35, 44-58. doi: 10.1016/j.cedpsych.2009.10.001

Goetz, T., Frenzel, A. C., Pekrun, R., Hall, N. C., \& Lüdtke, O. (2007). Between- and within-domain relations of students' academic emotions. Journal of Educational Psychology, 99, 715-733. doi:10.1037/00220663.99.4.715

Gottfried, A. E., Fleming, J. S., \& Gottfried, A. W. (2001). Continuity of academic intrinsic motivation from childhood through late adolescence: A longitudinal study. Journal of Educational Psychology, 93, 3-13. doi: $10.1037 / 0022-0663.93 .1 .3$

Hidi, S. (1990). Interest and its contribution as a mental resource for learning. Review of Educational Research, 60, 549-571.

Hidi, S. (2000). An interest researcher's perspective: The effects of extrinsic and intrinsic factors on motivation. In C. Sansone \& J. M. Harackiewicz (Eds.), Intrinsic and extrinsic motivation: The search for optimal motivation and performance (pp. 309-339). San Diego, CA: Academic Press. doi:10.1016/B978-012619070-0/50033-7

Hidi, S., \& Harackiewicz, J. M. (2000). Motivating the academically unmotivated: A critical issue for the 21st century. Review of Educational Research, 70, 151-179.

Hidi, S., \& Renninger, K. A. (2006). The four-phase model of interest development. Educational Psychologist, 41, 111-127. doi:10.1207/ s15326985ep4102_4

Hu, L., \& Bentler, P. M. (1999). Cutoff criteria for fit indexes in covariance structure analysis: Conventional criteria versus new alternatives. Structural Equation Modeling, 6, 1-55. doi:10.1080/10705519909540118
Hulleman, C. S., \& Harackiewicz, J. M. (2009). Promoting interest and performance in high school classes. Science, 326, 1410-1412. doi: $10.1126 /$ science. 1177067

Jacobs, J. E., Lanza, S., Osgood, D. W., Eccles, J. S., \& Wigfield, A. (2002). Changes in children's self-competence and values: Gender and domain differences across grades one through twelve. Child Development, 73, 509-527. doi:10.1111/1467-8624.00421

Karabenick, S. A., Woolley, M. E., Friedel, J. M., Ammon, B. V., Blazevski, J., Ree Bonney, C., ... Kelly, K. L. (2007). Cognitive processing of self-report items in educational research: Do they think what we mean? Educational Psychologist, 42, 139-151. doi:10.1080/ 00461520701416231

Katz, I., Assor, A., Kanat-Maymon, Y., \& Bereby-Meyer, Y. (2006). Interest as a motivational resource: Feedback and gender matter, but interest makes the difference. Social Psychology of Education, 9, 27-42. doi: 10.1007/s11218-005-2863-7

Köller, O., Baumert, J., \& Schnabel, K. (2001). Does interest matter? The relationship between academic interest and achievement in mathematics. Journal for Research in Mathematics Education, 32, 448-470. doi: $10.2307 / 749801$

Krapp, A. (2000). Interest and human development during adolescence: An educational-psychological approach. In J. Heckhausen (Ed.), Motivational psychology of human development (pp. 109-128). Oxford, England: Elsevier. doi:10.1016/S0166-4115(00)80008-4

Krapp, A., \& Lewalter, D. (2001). Development of interests and interestbased motivational orientations: A longitudinal study in school and work settings. In S. Volet \& S. Järvälä (Eds.), Motivation in learning contexts: Theoretical advances and methodological implications (pp. 201-232). London, England: Elsevier.

Kuckartz, U. (1995-2007). MAXQDA 2007 [Computer program]. Berlin, Germany: Verbi.

Lawless, J. E. (1987). Negative binomial and mixed Poisson regression. The Canadian Journal of Statistics, 15, 209-225.

Lipstein, R., \& Renninger, K. A. (2007). "Putting things into words": The development of 12-15-year-old students' interest for writing. In P. Boscolo \& S. Hidi (Eds.), Motivation and writing: Research and school practice (pp. 113-140). New York, NY: Elsevier.

Little, T. D. (1997). Mean and covariance structures (MACS) analyses of cross-cultural data: Practical and theoretical issues. Multivariate Behavioral Research, 32, 53-76. doi:10.1207/s15327906mbr3201_3

Marsh, H. W., Balla, J. R., \& McDonald, R. P. (1988). Goodness-of-fit indexes in confirmatory factor analysis: The effect of sample size. Psychological Bulletin, 103, 391-410. doi:10.1037/0033-2909 103.3.391

Marsh, H. W., Byrne, B. M., \& Yeung, A. S. (1999). Causal ordering of academic self-concept and achievement: Reanalysis of a pioneering study and revised recommendations. Educational Psychologist, 34, 155167. doi:10.1207/s15326985ep3403_2

Meredith, W. (1993). Measurement invariance, factor analysis and factorial invariance. Psychometrika, 58, 525-543. doi:10.1007/BF02294825

Meredith, W., \& Horn, J. L. (2001). The role of factorial invariance in modeling growth and change. In L. Collins \& A. G. Sayer (Eds.), New methods for the analysis of change (pp. 203-240). Washington, DC: American Psychological Association. doi:10.1037/10409-007

Muthén, L. K., \& Muthén, B. O. (1998-2008). Mplus user's guide (4th ed.). Los Angeles, CA: Author.

Nolen, S. B. (2007). Young children's motivation to read and write: Development in social contexts. Cognition and Instruction, 25, 219 270. doi:10.1080/07370000701301174

Pekrun, R., Goetz, T., Frenzel, A. C., Barchfeld, P., \& Perry, R. P. (2011) Measuring emotions in students' learning and performance: The Achievement Emotions Questionnaire (AEQ). Contemporary Educational Psychology, 36, 36-48.

Pekrun, R., vom Hofe, R., Blum, W., Frenzel, A. C., Goetz, T., \& Wartha, 
S. (2007). Development of mathematical competencies in adolescence: The PALMA longitudinal study. In M. Prenzel (Ed.), Studies on the educational quality of schools. The final report on the DFG Priority Programme (pp. 17-37). Münster, Germany: Waxmann.

Prenzel, M. (1992). The selective persistence of interest. In K. A. Renninger, S. Hidi, \& A. Krapp (Eds.), The role of interest in learning and development (pp. 71-98). Hillsdale, NJ: Erlbaum.

Raykov, T. (2004). Behavioral scale reliability and measurement invariance evaluation using latent variable modeling. Behavior Therapy, 35, 299-331. doi:10.1016/S0005-7894(04)80041-8

Reeve, J., Bolt, E., \& Cai, Y. (1999). Autonomy-supportive teachers: How they teach and motivate students. Journal of Educational Psychology, 91, 537-548. doi:10.1037/0022-0663.91.3.537

Renninger, K. A. (2000). Individual interest and its implications for understanding intrinsic motivation. In B. Sansone \& J. M. Harackiewitz (Eds.), Intrinsic and extrinsic motivation: The search for optimal motivation and performance (pp. 373-404). New York, NY: Academic Press. doi:10.1016/B978-012619070-0/50035-0

Renninger, K. A. (2009). Interest and identity development in instruction: An inductive model. Educational Psychologist, 44, 105-118. doi: 10.1080/00461520902832392

Renninger, K. A. (2010). Working with and cultivating the development of interest, self-efficacy, and self-regulation. In D. Preiss \& R. Sternberg (Eds.), Innovations in educational psychology: Perspectives on learning, teaching and human development (pp. 107-138). New York, NY: Springer.

Renninger, K. A., Ewen, L., \& Lasher, A. K. (2002). Individual interest as context in expository text and mathematical word problems. Learning and Instruction, 12, 467-491. doi:10.1016/S0959-4752(01)00012-3

Renninger, K. A., \& Hidi, S. (2002). Student interest and achievement: Developmental issues raised by a case study. In A. Wigfield \& J. Eccles (Eds.), Development of achievement motivation (pp. 173-195). San Diego, CA: Academic Press. doi:10.1016/B978-012750053-9/50009-7

Renninger, K., \& Hidi, S. (2011). Revisiting the conceptualization, measurement, and generation of interest. Educational Psychologist, 46, 168-184.

Renninger, K. A., \& Leckrone, T. (1991). Continuity in young children's actions: A consideration of interest and temperament. In L. Oppenheimer \& J. Valsiner (Eds.), The origins of action: Interdisciplinary and international perspectives (pp. 205-238). New York, NY: Springer.

Schiefele, U. (1991). Interest, learning, and motivation. Educational Psychologist, 26, 299-323.

Schiefele, U. (1998). Individual interests and learning-What we know and what we don't know. In L. Hoffmann, A. Krapp, K. A. Renninger, \& J. Baumert (Eds.), Interest and learning: Proceedings of the Seeon conference on interest and gender (pp. 91-104). Kiel, Germany: IPN.

Schiefele, U., Krapp, A., Wild, K.-P., \& Winteler, A. (1993). Der "Fragebogen zum Studieninteresse" (FSI). [The "questionnaire on study interest"]. Diagnostica, 39, 335-351.

Schiefele, U., Krapp, A., \& Winteler, A. (1992). Interest as a predictor of academic achievement: A meta-analysis of research. In K. A. Renninger, S. Hidi, \& A. Krapp (Eds.), The role of interest in learning and development (pp. 183-212). Hillsdale, NJ: Erlbaum.
Silvia, P. J. (2006). Exploring the psychology of interest. Oxford, England: Oxford University Press. doi:10.1093/acprof:oso/9780195158557 .001 .0001

Singh, S. (1997). Fermat's enigma: The epic quest to solve the world's greatest mathematical problem (2nd ed.). New York, NY: Walker.

Spinath, B., \& Steinmayr, R. (2008). Longitudinal analysis of intrinsic motivation and competence beliefs: Is there a relation over time? Child Development, 79, 1555-1569. doi:10.1111/j.1467-8624.2008.01205.x

Steenkamp, J. E. M., \& Baumgartner, H. (1998). Assessing measurement invariance in cross-national consumer research. Journal of Consumer Research, 25, 78-107. doi:10.1086/209528

Thurstone, L. L. (1947). Multiple-factor analysis: A development and expansion of the vectors of mind. Chicago, IL: University of Chicago Press.

Todt, E., \& Schreiber, S. (1998). Development of interest. In L. Hoffmann, A. Krapp, \& J. Baumert (Eds.), Interest and learning (pp. 25-40). Kiel, Germany: IPN.

Tracey, T. J. G. (2001). The development of structure of interests in children: Setting the stage. Journal of Vocational Behavior, 59, 89-104. doi: $10.1006 /$ jvbe. 2000.1787

Tsai, Y.-M., Kunter, M., Lüdtke, O., Trautwein, U., \& Ryan, R. (2008). What makes lessons interesting? The role of situation and person factors in three school subjects. Journal of Educational Psychology, 100, 460472. doi:10.1037/0022-0663.100.2.460

Vandenberg, R. J., \& Lance, C. E. (2000). A review and synthesis of the measurement invariance literature: Suggestions, practices, and recommendations for organizational research. Organizational Research Methods, 3, 4-70. doi:10.1177/109442810031002

Watt, H. M. G. (2004). Development of adolescents' self-perceptions, values, and task perceptions according to gender and domain in 7ththrough 11 th grade Australian students. Child Development, 75, 15561574. doi:10.1111/j.1467-8624.2004.00757.x

Wigfield, A., \& Cambria, J. (2010). Students' achievement values, goal orientations, and interest: Definitions, development, and relations to achievement outcomes. Developmental Review, 30, 1-35.

Wigfield, A., Eccles, J. S., Mac Iver, D., Reuman, D., \& Midgley, C. (1991). Transition to early adolescence: Changes in children's domainspecific self-perceptions and general self-esteem across the transition to junior high school. Developmental Psychology, 27, 552-565. doi: 10.1037/0012-1649.27.4.552

Woolley, M. E., Bowen, G. L., \& Bowen, N. K. (2004). Cognitive pretesting and the developmental validity of child self-report instruments: Theory and applications. Research on Social Work Practice, 14, 191 200. doi:10.1177/1049731503257882

Woolley, M. E., Bowen, G. L., \& Bowen, N. K. (2006). The development and evaluation of procedures to assess child self-report item validity. Educational and Psychological Measurement, 66, 687-700. doi $10.1177 / 0013164405282467$

Zimmerman, B. J., \& Kitsantas, A. (1999). Acquiring writing revision skills: Shifting from process to outcome self-regulatory goals. Journal of Educational Psychology, 91, 241-250. doi:10.1037/0022-0663.91.2.241 


\section{Appendix}

\section{Items Used in the Study to Assess Interest}

I am interested in mathematics.

I like to read books and solve brain teasers related to mathematics.

Doing mathematics is one of my favorite activities.

I often find that the things we deal with in mathematics are really exciting.
After a math class, I am often curious about what we are going to do in the next lesson.

I would like to find out much more about some of the things we deal with in our mathematics class. 